\title{
Genetic Considerations for the Restoration of Smooth Cordgrass (Spartina alterniflora) Within lits Native Range
}

Open-File Report 2006-1305

U.S. Department of the Interior U.S. Geological Survey 


\section{Genetic Considerations for the Restoration of Smooth Cordgrass (Spartina alterniflora) Within Its Native Range}

By Steven E. Travis, C. Edward Proffitt, and Keith R. Edwards

Open-File Report 2006-1305 


\section{U.S. Department of the Interior DIRK KEMPTHORNE, Secretary}

\section{U.S. Geological Survey Mark D. Myers, Director}

\section{U.S. Geological Survey, Reston, Virginia 2006}

For product and ordering information:

World Wide Web: http://www.usgs.gov/pubprod

Telephone: 1-888-ASK-USGS

For more information on the USGS — the Federal source for science about the Earth, its natural and living resources, natural hazards, and the environment:

World Wide Web: http://www.usgs.gov

Telephone: 1-888-ASK-USGS

Suggested citation:

Travis, S. E., Proffitt, C. E., and Edwards, K. R., 2006, Genetic considerations for the restoration of smooth cordgrass (Spartina alterniflora) within its native range: U.S. Geological Survey Open-File Report 2006-1305, 11 pages.

Any use of trade, product, or firm names is for descriptive purposes only and does not imply endorsement by the U.S. Government.

Although this report is in the public domain, permission must be secured from the individual copyright owners to reproduce any copyrighted material contained within this report. 


\section{Contents}

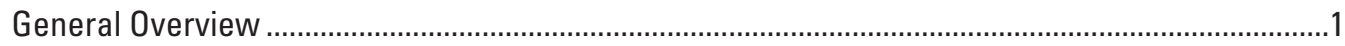

Applying genetic principles to the restoration of salt marsh communities ……..............................5

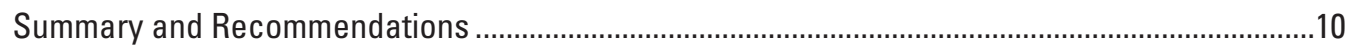

References Cited...................................................................................................................

\section{Figures}

1. Salt marsh developing on dredged sediments in the Sabine National Wildlife Refuge, La..... 2

2. An example of the role of genetic variation in the adaptation of a population to a change in

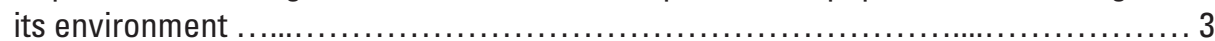

3. The range of elevations at which smooth cordgrass is capable of colinizing will be determined by variation in traits related to wateruptake/conservation................. 3

4. The change in inbreeding over time at varying population size .......................... 4

5. An example of outbreeding depression brought about by translocating individuals across populations adapted to different environmental conditions........................... 4

6. Smooth cordgrass patches growing along the margin of a borrow ditch in a created

7. A satellite photo of the western Calcasieu Lake estuary where it overlaps with the Sabine

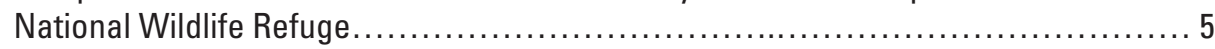

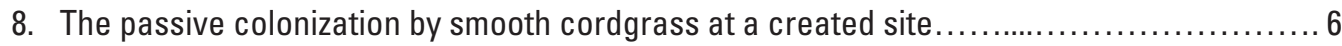

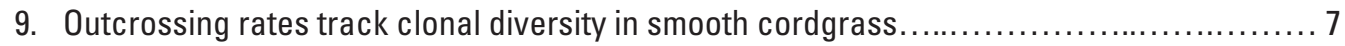

10. The predicted change in clonal diversity over time for an initial seedling recruiter.......... 7

11. Increasing clone size associated with increasing genetic diversity in older marshes........ 7

12. Stem density and average stem height differences between smooth cordgrass clones...... 8

13. Smooth cordgrass clones classified as functional types according to the light and crowding conditions they provide for other colonizing plant species........................... 9

14. Genetic isolation-by-distance in smooth cordgrass....................................... 9

15. The effects of smooth cordgrass transplantation on survival and growth .................. 10 


\section{Tables}

1. A comparison of genetic diversity among four smooth cordgrass populations ..........................6 


\title{
Genetic Considerations for the Restoration of Smooth Cordgrass (Spartina alterniflora) Within Its Native Range
}

\author{
By Steven E. Travis, C. Edward Proffitt, and Keith R. Edwards
}

Abstract

In order to remain viable over many generations, plant populations require the ability to respond adaptively to a changing environment. Such adaptive potential is directly controlled by underlying genetic variation, which can be measured in terms of both heterozygosity at the individual level and clonal, or genotypic diversity, at the population level. This report summarizes research relating to the importance of genetic diversity in the restoration of salt marsh smooth cordgrass, Spartina alterniflora, a dominant member of low elevation intertidal marshes throughout the northern Gulf of Mexico and Atlantic Coasts of North America. Recent research has indicated that S. alterniflora is a partially clonal species characterized by the recruitment of seedlings exclusively during the initial colonization phase of population establishment. A major consequence of this finding is that clonal diversity generally peaks rather early in the development of a restored marsh, depending on the rate of natural immigration and/or the clonal diversity of planting units, and then undergoes a steady decline over geological time spans because of stochastic mortality and intraspecific competition. Low levels of clonal diversity resulting from restricted immigration or clonally depauperate planting materials in turn places strict limits on opportunities for outcrossing in a species known to suffer from severe inbreeding depression. Low clonal diversity may further lead to declining levels of heterozyosity of individual clones, which directly affects competitive ability. In addition, the planting of genetically diverse plant materials should take into account the genetic and adaptive differentiation that takes place when plant populations are widely separated in space and/or dwell under varying sets of environmental conditions. Thus, steps should be taken to ensure that $S$. alterniflora clones developed for restorative plantings are both genetically diverse and sufficiently pre-adapted to environmental conditions at the proposed restoration site. This can be achieved by growing plant materials collected from local sources and by either taking care to maintain relatively high levels of clonal diversity or by planting clones at sufficiently low densities that they will not quickly grow to monopolize a restoration site without first producing several generations of sexual recruits through crosses with nearby native populations.

\section{General Overview}

The ultimate goal of ecosystem restoration is the establishment of structural and functional equivalency between restored and natural communities. In other words, the restorationist generally desires that the restored community will develop towards a similar suite of species, in similar proportions and exhibiting similar levels of productivity, nutrient cycling, etc., to some predetermined target or reference community (fig. 1). For many restoration projects, a logical first step in this process is the reintroduction of the dominant primary producers characterizing the target community, which then act as ecosystem engineers by rapidly improving the conditions for colonization by other, more sensitive species (e.g., Bruno, 2000). Because restoration biology is so often concerned with the factors affecting the successful establishment of plant populations, many of the guiding principles of methodology have been borrowed from population biology. Population biology, in turn, relies on the principles of population ecology (or the study of how populations interact with the various elements of their environment) and population genetics (or the study of how gene pools are altered over time in response to these interactions). Thus, it is instructional to begin any consideration of the role of genetics in restoration biology with some basic principles of population genetics.

Plants, like all organisms, are able to persist unaided in nature only if they are properly adapted to their surrounding environment. Furthermore, if their environment should change in a way that directly impacts their ability to survive and reproduce, their persistence will depend on their ability to alter their adaptations accordingly. At the heart of each adaptation, be it morphological or physiological, is a single gene or suite of genes controlling its expression. Even adaptations that are "adjustable," that is adaptations that plants can alter in real time as their environment undergoes rapid changes, are only adjustable within limits that are dictated by underlying genes. 


\section{(A)}

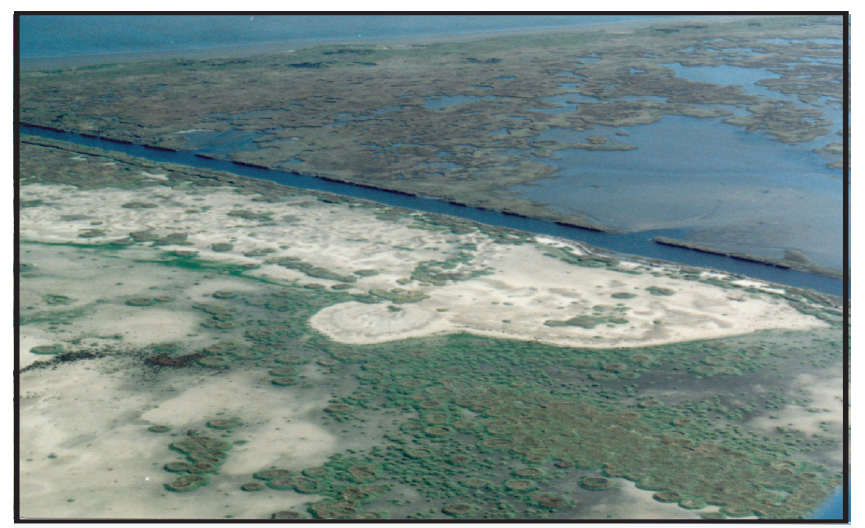

(B)

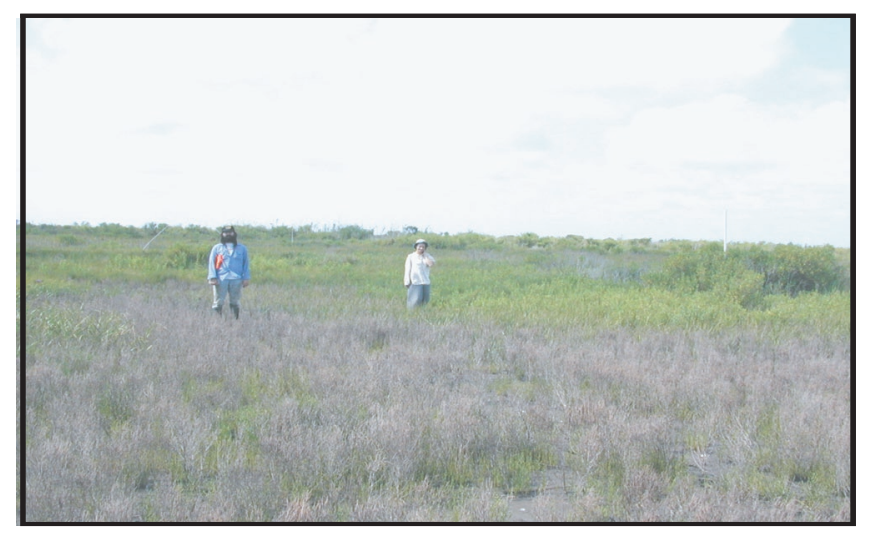

(C)

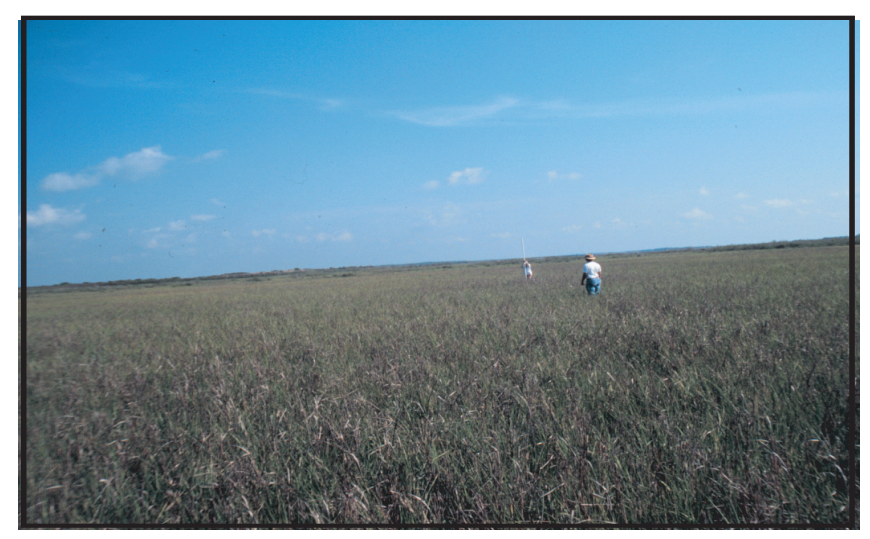

Figure 1. Salt marsh developing on dredged sediments in the Sabine National Wildlife Refuge, La.: (A) an aerial perspective of a 1- to 2-year-old site showing circular smooth cordgrass (Spartina alterniflora) clones, (B) a 4- to 6-year-old site, with subjects positioned to mark the edges of two consecutive years' growth of a single smooth cordgrass clone, (C) a 14- to 16-year-old marsh dominated by typical salt marsh grasses: smooth cordgrass, saltmeadow cordgrass (Spartina patens), and saltgrass (Distichlis spicata).
In reality, the fate of individual plants is rarely a matter of direct concern, but rather the fate of populations. Populations, like individuals, are controlled by genes, although in this case it is the entire collection of genes dispersed across all of the member individuals, otherwise known as the "gene pool," that comprises the operational unit upon which the environment acts. Through sexual reproduction and the cellular processes of random assortment and recombination, this gene pool is reshuffled with each passing generation, giving rise to a nearly limitless supply of individuals upon whose suites of adaptations the local environment can act. Thus, a population is provided with an effective mechanism for altering its adaptations over time in response to a fluctuating environment.

In order for two individuals to express variation in an adaptive trait they must also vary at the level of their genes. This variation is constantly being generated through a natural process of random mutation, which simply involves an alteration of the sequence of nucleotide building blocks within a gene. Each time a gene takes on a slightly altered form, a new "allele" is said to have arisen. In theory, the number of alleles representing any given gene is limited only by the number of individuals comprising a population. At the level of genes then, it is changes in the frequencies of these alleles, each of which affects some outward adaptation in a slightly different way, that drives the overall level of adaptation exhibited by a population (fig. 2 is a classic example of the role of genetic variation in the adaptation of a population to a change in its environment).

If one assumes that populations exist along a continuum of genetic variation from one extreme, in which all individuals possess exactly the same alleles for every gene, to another, in which every individual possesses a completely unique set of alleles, it is easy to visualize how populations may differ in their responsiveness to environmental change. A population composed of a genetically identical set of individuals will have very little ability to respond, even if it is capable of sexual reproduction, because no new allelic combinations will be possible. On the other hand, a population in which no two individuals possess the same alleles for any given gene is not likely to be particularly well adapted to any particular set of environmental variables, and in order to avoid local extinction may be forced to adjust its allele frequencies more rapidly than would be possible through a limited number of breeding cycles. Thus, the ideal population exists somewhere in the middle of this genetic diversity continuum and exhibits a preponderance of individuals with matching alleles that render them generally well adapted to current environmental conditions, while harboring a sufficient quantity of alternative alleles to enable the population to adjust as conditions change.

For the purpose of restoring populations, there are several critical elements to consider. First, because every environment, no matter how stable, is constantly fluctuating on some level, every viable population will require genetic variation in order to make adjustments. A straightforward 


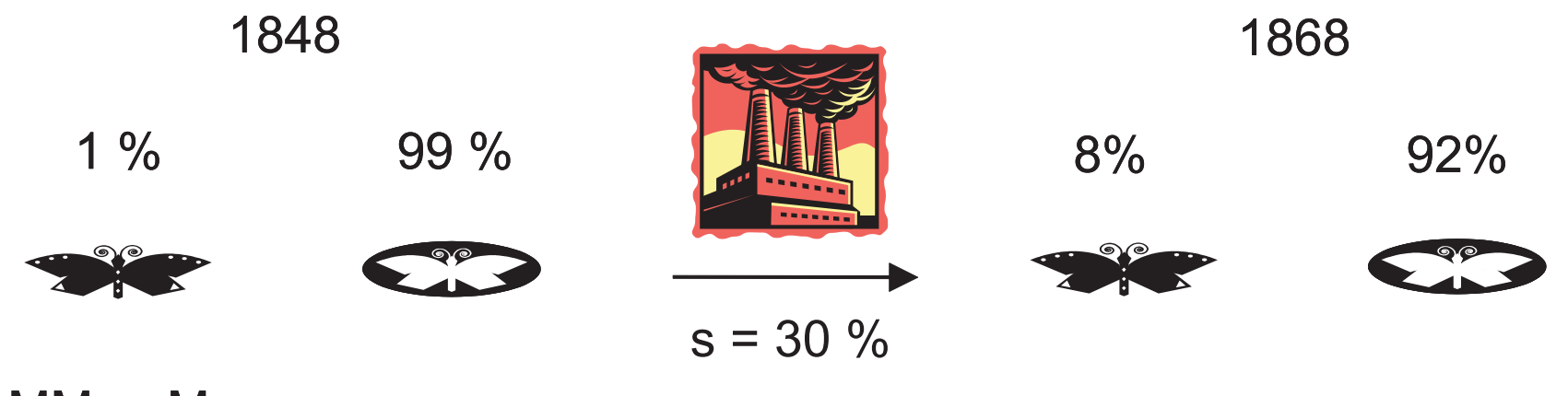

\section{MM or $\mathrm{Mm} \quad \mathrm{mm}$}

Figure 2. A classic example of the role of genetic variation in the adaptation of a population to a change in its environment. Prior to the industrial revolution, peppered moth populations in England were dominated by the nonmelanistic color morph (an adaptation for avoiding predators while resting on the lichen-covered bark of trees). During the industrial revolution, the burning of coal released soot into the environment, darkening the bark of trees and thus favoring the melanistic color morph. This color difference is controlled by a single gene, represented with " $\mathrm{m}$ " in its nonmelanistic, recessive form, and with " $\mathrm{M}$ " in its melanistic, dominant form. The rate of increase in the frequency of the melanistic color morph can be predicted from population genetics theory if its relative advantage over the nonmelanistic form, s (30\% in this case), is known.

example involves the introduction of a disease organism into a restored population. If a gene that controls disease resistance exists in only one form, and that form happens to be ineffective against the introduced pathogen, then the entire population may be lost. If, on the other hand, that gene exists in multiple forms, there is an improved chance that some individuals will harbor resistance and will thus enable the population to persist. In addition, it is important to consider that every environment is heterogeneous on some level, and without genetic variation a population may lack the ability to fully exploit that environment. For example, consider the situation in which elevation, and thus the availability of water, varies across an otherwise homogeneous environment (fig. 3). If every individual in the population is genetically predisposed to growing where water is readily available, then all but the lowest elevations within a site may remain uncolonized.

The level of genetic variation exhibited by a population will also impact its ability to propagate itself through sexual reproduction, because every gene in higher organisms exists in duplicate, with one copy coming from the maternal parent and the other from the paternal parent. Many new alleles arising through mutation will, by chance, be maladapted to prevailing environmental conditions; however, the environment will only be capable of eliminating these alleles if they are not masked by the normal, or wild type allele, represented in their homologous gene. If the alleles are masked, they are free to build up in a population as recessive alleles and to establish a mutational load. This mutational load will remain largely hidden from the environment unless genetic variation falls below the level at which individuals begin to reproduce with their close genetic relatives, or in the case of plants, with themselves, through the process of self-fertilization (fig. 4). Such inbreeding will greatly increase the probability that duplicate maladapted alleles will be brought together within a single individual and be expressed as a maladapted trait. To illustrate this process, consider the situation in which a maladapted recessive allele exists, along with a wild type allele, in only one individual of a large population. As long as this individual crosses with other, genetically distinct individuals, there is no chance its offspring will inherit two copies of the recessive allele; whereas, if the population becomes so small that it is forced to cross with itself, one in every four of its offspring will, by chance, express this maladapted trait. When many genes become involved in this process, virtually all of an individual's offspring are likely to decline in their level of adaptation to the local environment in a process known as "inbreeding depression."

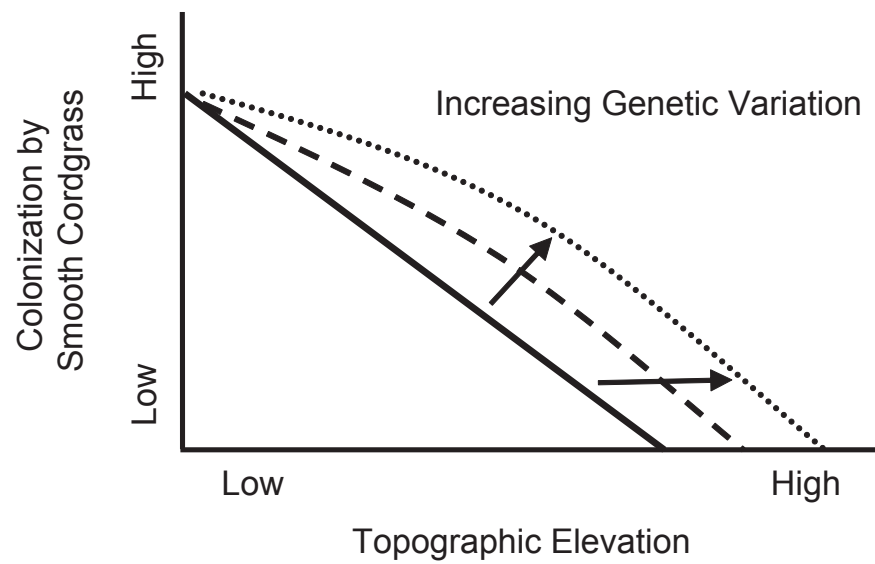

Figure 3. For a dominant intertidal plant such as smooth cordgrass, the range of elevations at which it is capable of colonizing will be determined, at least in part, by the amount of genetic variation in traits related to water uptake/conservation. In this figure, the solid line represents a clonally homogeneous population, while the dashed and dotted lines represent increasing levels of clonal diversity. 


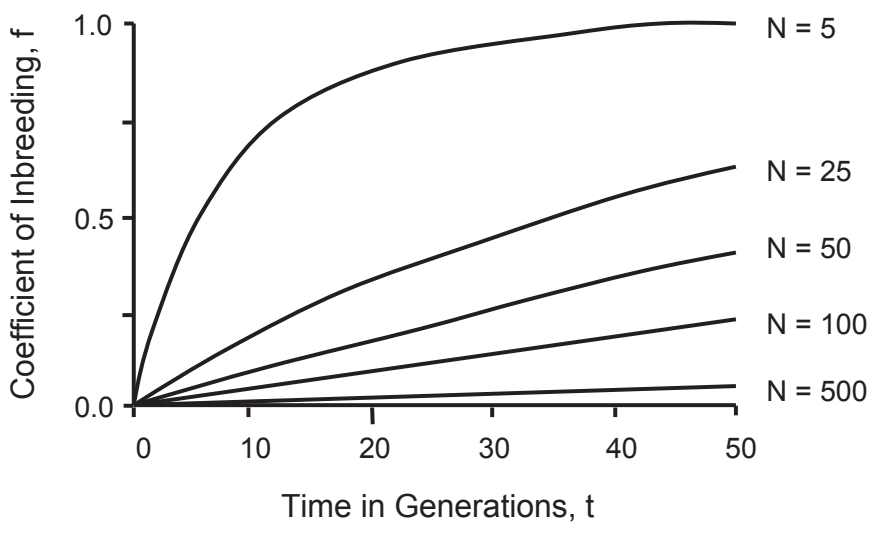

Figure 4. The change in inbreeding over time at varying population size $=\mathrm{N}$. The inbreeding coefficient is a measure of the average probability that any given gene will be represented by identical alleles inherited from a common ancestor.

A second genetic consideration for restoration is whether and at what frequencies the alleles present in the restored population match those that are adaptive under local environmental conditions. For example, if the plant species in question is characterized by a broad geographical range encompassing a wide range in temperature, then a population drawn from the colder end of the range would likely possess a set of alleles for cold tolerance that would be poorly adapted to a site existing at the warmer end of the range. Furthermore, even if two environments appear to be identical, if the populations occupying them are widely separated in space and have had little opportunity for allelic exchange, they will likely have evolved alternative sets of alleles for coping with their respective environments. Bringing these populations together and allowing them to interbreed may create maladapted combinations of alleles, because most adaptations are affected by several different genes, and it is the interactions among the alleles for these genes as much as the alleles themselves that control the expression of outward character states. If these combinations are broken, the level of adaptation may decline precipitously in a process known as outbreeding depression (fig. 5). Thus, if there is a good chance that a restored population will be interbreeding with natural populations in the area, it is critically important that the restored population should harbor similar alleles. In order to ensure that this is the case, populations should never be restored from individuals collected long distances from the restoration site. Gauging this distance can be difficult, but a good rule-of-thumb is to consider that if two populations had no conceivable chance of genetic exchange under natural conditions, they should probably not be allowed to exchange alleles in the context of restoration either.

In summary, the ideal restored population should harbor an amount of genetic diversity and a suite of alleles that is consistent with other natural populations in the local region. Since the local environment is constantly reworking this variation, it is safe to assume that what we can observe from natural populations is almost certainly what works best under prevailing conditions. To seriously alter this variation is to create a population that is maladapted and which will be extremely unlikely to meet long-term restoration goals.

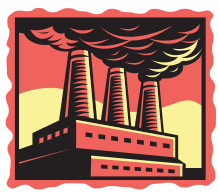

$\mathrm{N}=1,000$

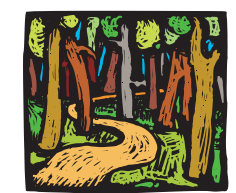

$\mathrm{N}=50$

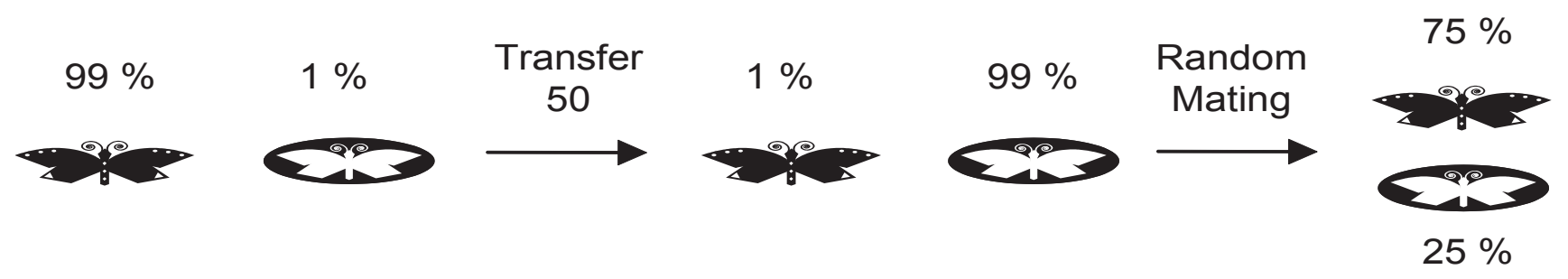

Figure 5. An example of outbreeding depression brought about by translocating individuals across populations adapted to different environmental conditions. A large (size $N=1,000$ ), predominantly melanistic population of peppered moths living in a sooty environment is used to augment a small $(N=50)$, nonmelanistic population living in a clean environment, resulting - after a single generation of random mating — in a population of mostly melanistic individuals lacking in the cryptic coloration necessary for predator avoidance. 


\section{Applying Genetic Principles to the Restoration of Salt Marsh Communities}

\author{
Smooth cordgrass (Spartina alterniflora) is a
} dominant member of low elevation, intertidal salt marshes throughout much of the northern Gulf of Mexico and Atlantic coasts of the United States and has been used extensively as an aid to offsetting coastal land loss. This is a robust species, capable of tolerating relatively extreme environmental conditions such as salinities approaching $70 \mathrm{ppt}$, at least in part caused by its clonal growth habit (fig. 6). Clonality enables the plant, or genet, to spread its risk of mortality over many hundreds or thousands of individual stems, or ramets, some of which may fortuitously find themselves growing under relatively benign conditions, even when the majority are under extreme stress. Thus, smooth cordgrass is able to provide a certain buffering capacity for the community as a whole, while providing critical habitat for both invertebrates (shellfish, crustaceans, etc.) and vertebrates (larval fish, waterfowl, semiaquatic rodents and their associated predators) (Travis and others, 2002a).

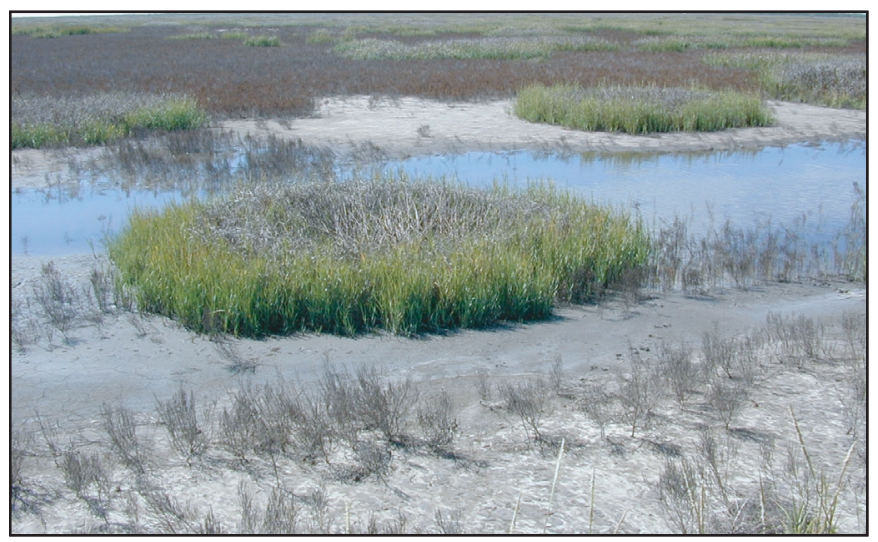

Figure 6. Smooth cordgrass patches growing along the margin of a borrow ditch resulting from the construction of a containment levee around a created wetland. Because of the rarity of flooding on many created sites, standing water salinites can reach very high levels, giving an advantage to clones that are spread out over a relatively broad elevational gradient.

The various methods used to restore smooth cordgrass to intertidal salt marsh generally fall into two categories, passive colonization and active planting. Whether the restoration site has been intentionally created from open water, such at through the deposition of sediments dredged from nearby navigation channels, or whether it is undergoing mitigation following some high impact disturbance such as a chemical spill, active planting would seem to provide the advantage of more rapid coverage of the site. Passive colonization, however, can be a relatively rapid process if a ready supply of potential immigrants exists in the immediate vicinity of the restoration and may offer the advantage of a more diverse gene pool that is preadapted to the suite of environmental conditions existing at the site.

In order to shed light on how passive colonization compares to active planting in maintaining genetically viable populations over the long-term, considerable effort by researchers at the USGS National Wetlands Research Center (Lafayette, La.), in cooperation with McNeese State University (Lake Charles, La.) and the University of Louisiana at Lafayette, has gone into studying the dynamics of passive colonization by smooth cordgrass at both natural and created sites in the gulf coast region. This work began in 1998 at the Sabine National Wildlife Refuge (Sabine NWR) in southwestern Louisiana, where four separate marsh creation projects have restored over 1,000 hectares of emergent salt marsh since 1983 (fig. 7). These sites are interspersed with small areas of undisturbed, native marsh, providing an opportunity for comparison with an appropriate target ecosystem. Based on aerial photographs of the area, which allow us to track the history of saltwater intrusion into the surrounding Calcasieu Lake estuary, we have dated the oldest salt marshes at approximately 50 years old.

Passive colonization of created sites is dependent on the rafting of both floating vegetation mats, which transport fragments of clones, and seeds (fig. 8). Thus, initial colonization is entirely dependent on at least partial inundation. Nevertheless, even at sites where episodes of tidal inundation are rare, clonal spread and sexual reproduction, combined with occasional inundation resulting from sustained winds blowing water into the estuary from the Gulf of Mexico to the south, have been sufficient to bring about $>50 \%$ colonization of sites as large as 300 hectares within a period of just 3 years (Proffitt and Young, 1999). Although smooth cordgrass has generally been noted for its low seed viability, widespread seedling recruitment was found to occur on bare sediments during peak years at the Sabine NWR.

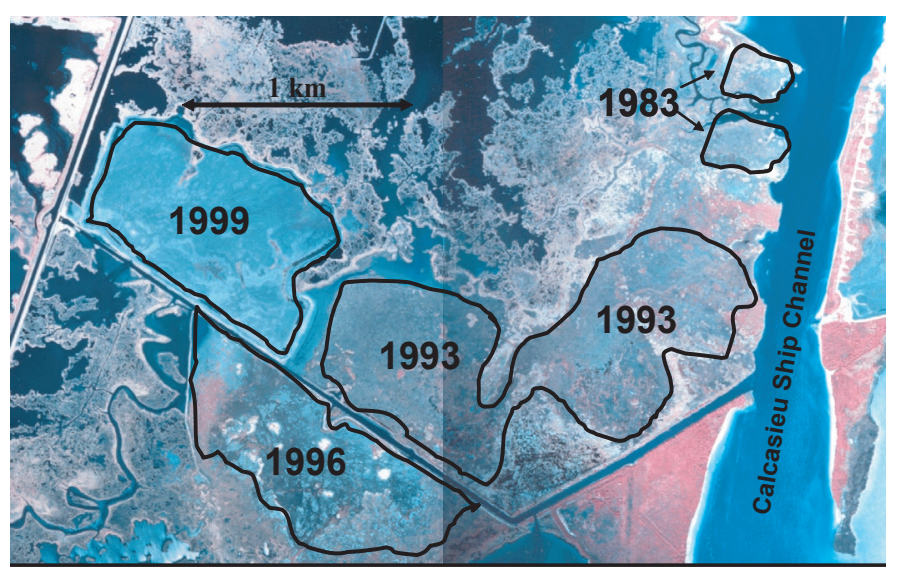

Figure 7. A satellite photograph of the western Calcasieu Lake estuary where it overlaps with the Sabine National Wildlife Refuge. Four salt marsh sites were created from dredged sediments by the U.S. Army Corps of Engineers in 1983, 1993, 1996, and 1999 (outlined in black). 
(A)

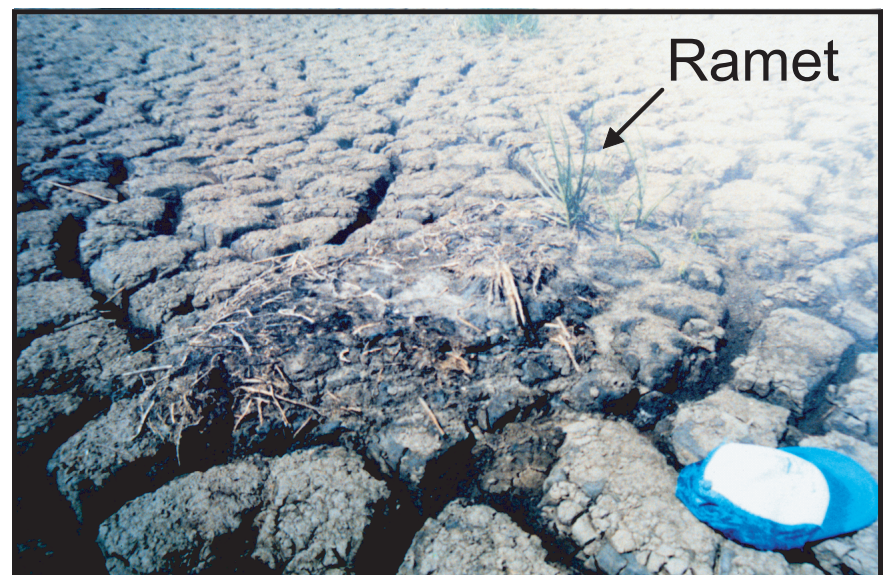

(B)

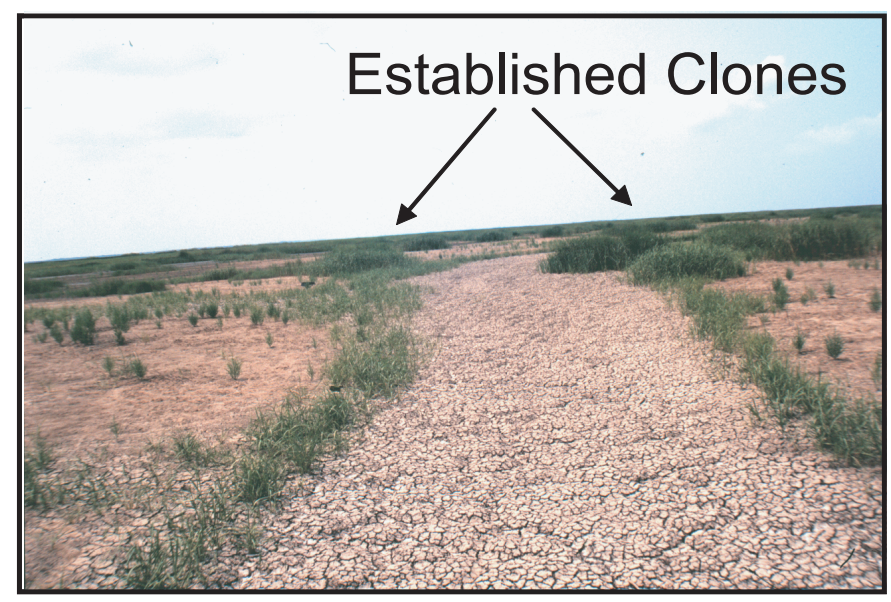

Figure 8. The passive colonization by smooth cordgrass at a created site: $(A)$ a vegetation mat with a live ramet sprouting in the upper right portion of the photograph, $(B)$ a seedling fringe growing on either side of a dry tidal creek (established clones can be seen growing in the background).

From a population genetics perspective, a logical first question in evaluating the adaptive potential of restored smooth cordgrass populations is how quickly are natural levels of genetic diversity attained? To answer this question, populations growing on three created sites ranging in age from 2 to 15 years were compared to an adjacent reference marsh using neutral molecular markers in the form of amplified fragment length polymorphisms (AFLPs) run on a random sample of 20-35 individuals per site (Travis and others, 2002b). Overall, the findings indicated that the gene pool available for colonization was sufficiently diverse to establish equivalent levels of diversity across all populations within just 2 years (table 1), buoyed by an estimated migration rate of 3.6 migrants (either pollen or seeds) per generation. Population
Table 1. A comparison of genetic diversity among four smooth cordgrass populations - three created and one natural (reference), varying in age from 1 to 50 years at the Sabine National Wildlife Refuge: $\langle\mathrm{H}>=$ average heterozygosity, or the average proportion of genetic loci at which a randomly chosen individual would be expected to possess two alternate alleles; $\langle\mathrm{P}\rangle=$ proportion of polymorphic loci, where a polymorphic locus is defined as having two alleles, each at a frequency of $<0.95$.

\begin{tabular}{llll}
\hline Polulation & Age (Yrs) & $\langle\mathrm{H}\rangle$ & $\langle\mathrm{P}\rangle$ \\
\hline & & & \\
Reference & $40-50$ & 0.21 & 0.77 \\
1983 Site & 14 & 0.24 & 0.82 \\
1993 Site & 4 & 0.19 & 0.55 \\
& & & \\
1996 Site & 1 & 0.26 & 0.68 \\
\hline
\end{tabular}

genetics theory predicts that an average of just 1 migrant per generation is sufficient to create panmixis, or the complete homogenization of diverse gene pools over time, and thus the adaptive potential of the smooth cordgrass populations growing on created sites at the Sabine NWR appears to be high.

In clonal species such as smooth cordgrass, genetic diversity, which is calculated as an overall population average using a variety of statistics such as average heterozygosity, may paint only half of the picture. This is because clonal species have the capacity to colonize entire sites starting from just one or several clones. Even if these clones were highly heterozygous (i.e., genetically diverse) the adaptive potential of the population would still be limited, as would the potential for avoiding the deleterious effects of inbreeding. Thus, another important question is how quickly are natural levels of clonal diversity attained on passively colonized sites? In this case, a clear relationship was observed between clonal diversity and marsh age when 12 ramets were sampled from each of 20 patches at 4 sites, with the lowest diversity occurring on the youngest sites, then increasing to a predicted maximum of $>0.90$ (on a scale of 0 to 1 ) at approximately 30 years, followed by a gradual decline (Travis and others, 2004). Of equal importance, outcrossing rates were found to track clonal diversity very closely (fig. 9), and the consequences of self-fertilization were severe, with the evidence suggesting that selfed seedlings were rarely surviving to reach sexual maturity.

One of the more illuminating findings to come from studies of clonal diversity in smooth cordgrass is that seedling recruitment occurs almost exclusively on bare substrate. This helps to explain not only the aforementioned 


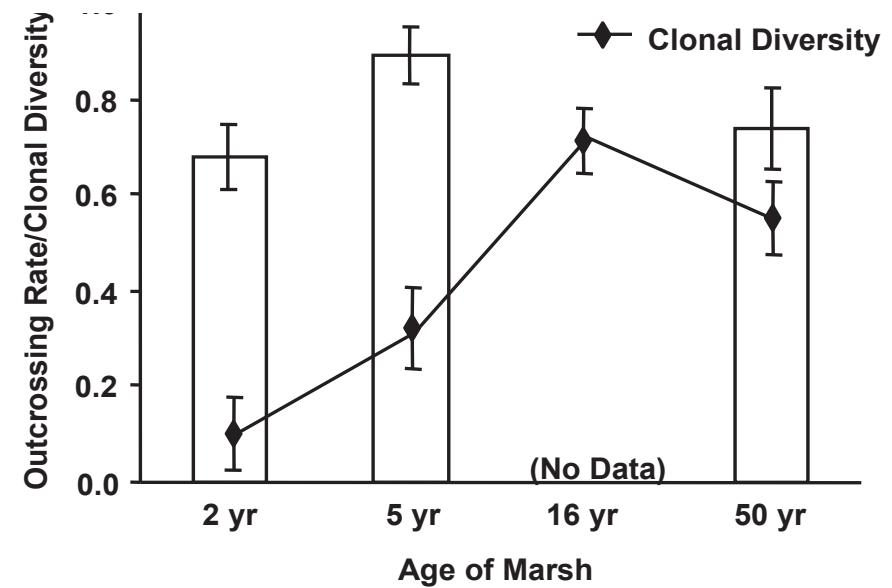

Figure 9. Outcrossing rates track clonal diversity very closely among four smooth cordgrass populations varying in age from 2 to 50 years. Here, outcrossing is defined as any sexual cross that does not involve self-fertilization, and clonal diversity is measured as the complement of the Simpson diversity index.

decline in clonal diversity beyond a marsh age of 30 years, but also the lack of seedling recruitment in established smooth cordgrass populations that has been noted by other researchers (e.g., Hartman, 1988). Clonal plants are considered to fall into two distinct categories based on their seed dispersal capabilities: (1) those with large seeds adapted for germinating in established populations, known as repeated seedling recruiters, and (2) those with small seeds adapted for longrange dispersal and colonization of novel environments, known as initial seedling recruiters. The latter category, which we now know to include smooth cordgrass, exhibits declining clonal diversity over time in established populations, because in the absence of new clones a gradual attrition of the founding population will occur through stochastic mortality and possibly through competition if some clones are competitively superior. This is an extremely important finding for restoration, because it suggests that smooth cordgrass populations founded from a small number of clones, whether through passive colonization or active planting, will peak at very low levels of clonal diversity and only need to experience small additional losses to achieve a genetic monoculture (fig. 10 ), which would represent a dead-end from both an adaptive and a reproductive perspective.

In order to evaluate whether such monocultures are ever actually achieved under natural conditions, as well as how the negative consequences of low clonal diversity may be avoided in very old populations, a broader comparison of natural populations was conducted, encompassing the entire Louisiana coastline (Travis and Hester, 2005). Population ages were estimated from published sediment core data that utilized radiocarbon dating throughout the Mississippi deltaic plain. In total, 8 natural populations ranging in age from approximately 6 to 1,500 years were compared for both clonal diversity and maximum clone diameter, and the decline in clonal diversity noted in the previous study was found to hold true over geologic time, with a decrease in diversity of approximately 1 percent per 100 years. A concomitant increase in the maximum diameter of individual clones was noted, indicating that older marshes are increasingly dominated by a decreasing number of competitively superior clones over time. Evidence that these clones were drawing their advantage from comparatively high levels of genetic diversity came in the form of an increasingly positive relationship between average heterozygosity and clone size with increasing age of marsh (fig. 11). This is the first real indication of a direct link between genetic diversity at the individual level and fitness in smooth cordgrass. In

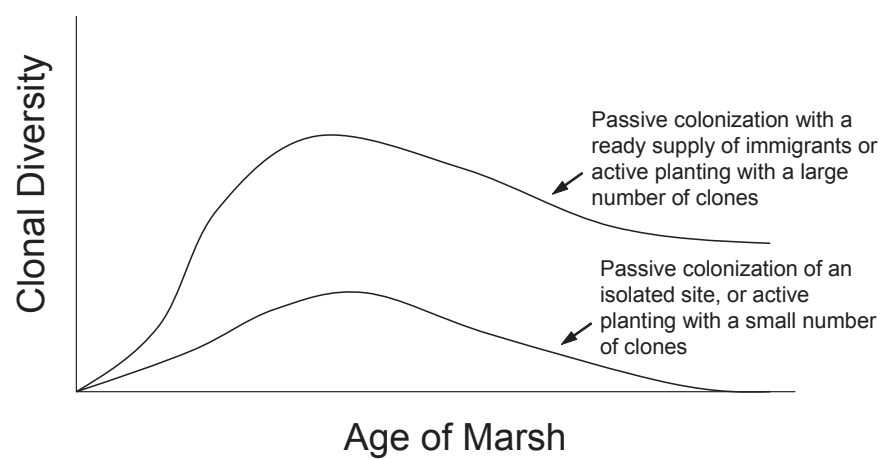

Figure 10. The predicted change in clonal diversity over time for an initial seedling recruiter such as smooth cordgrass. The initially slow increase in clonal diversity is caused by the spatial isolation of early colonizers, such that sexual reproduction is only possible through self-fertilization, and the majority of the seed progeny suffer mortality from inbreeding depression. The steady state achieved in the upper plot might be expected with a relatively high frequency of low-level disturbances, which occasionally create bare substrate for colonization by seedlings. Note that the lower plot quickly declines to a monoculture caused by the gradual loss of most of the founding clones.

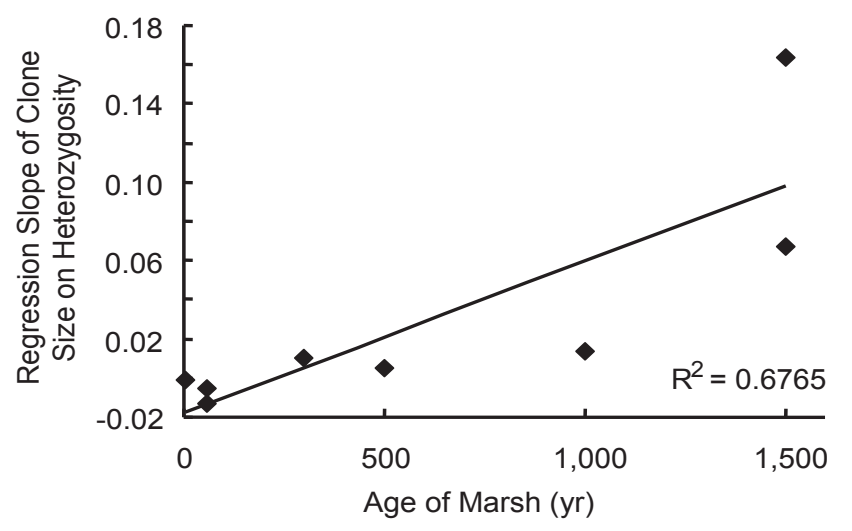

Figure 11. Increasing clone size associated with increasing genetic diversity (heterozygosity) in older marshes, indicating the competitive advantage enjoyed by highly heterozygous clones. 
addition, this work revealed a mechanism by which long-lived populations maintain relatively high levels of outcrossing, via the fragmentation of clones and intermingling of ramets from distinct genets.

Because each of the aforementioned studies draws inferences about the adaptive potential of populations from neutral DNA markers, i.e., nongene sequences that are invisible to natural selection, it is important to address whether the genetic differences noted among clones actually translate into adaptive differences linked to survival, growth, and reproduction. For this purpose, a large common-garden experiment was conducted at a newly created site in the Sabine NWR (Proffitt and others, 2003). A total of 5 large clones that had naturally colonized a separate area of restored marsh were transplanted for this experiment, with 35 separate plantings consisting of 10 ramets each, established in a randomized block configuration. Each planting was measured for survival and growth over a period of 18 months, and higher levels of variation among than within clonal replicates was taken as evidence of heritable differences. Mortality as a result of transplantation shock varied significantly among clones and was directly related to differences in elevation across the experimental site for 2 of the 5 clones. One clone was superior to all others at achieving rapid lateral growth at all elevations. Notably, the clones exhibiting the highest stem densities also tended to display the shortest mean stem heights, while the sparsest clones tended to be the tallest, showing a clear tradeoff in resource allocation (fig. 12). Overall, these differences highlight the structural heterogeneity imparted to smooth cordgrass communities by interclonal variation in morphologies and ecological tolerances.
As a means of directly assessing the importance of clonal diversity to the development of species-rich salt marsh plant communities, two independent experiments were conducted. First, the growth experiment just described was revisited after 3.5 years, at which time all 5 experimental clones were measured for colonization by other plant species, both along their peripheries and in their interiors, which tend to undergo a natural process of senescence over time (Proffitt and others, 2005). Whether a particular smooth cordgrass clone tended to facilitate or suppress colonization tended to depend not only on the light and water requirements of the colonizing species, but also on the average per-unit biomass exhibited by the clone, which was a general indicator of light and heat penetration to the soil surface (fig. 13). Using two of the more common colonists, the annuals Salicornia bigelovii and Aster subulatus var. subulatus, as examples, the abundance of each species varied by location, with $S$. bigelovii preferring the edges of smooth cordgrass clones and A. subulatus preferring to colonize clone centers. Location also affected $S$. bigelovii's performance relative to each experimental clone, while A. subulatus consistently performed poorly relative to the tallest clone in the experiment because of an apparent intolerance for shade. A second experiment explored the potential facilitative effects of smooth cordgrass on a perennial shrub, Baccharis halimifolia, by comparing the rate of seed settling and seedling growth inside and outside of clones. The experiment showed that while significantly fewer seeds settled inside clones, seedlings nevertheless gained a clear advantage in terms of both survival and growth (Egerova and others, 2003). Such preferences make it very conceivable that a smooth cordgrass community characterized by low clonal

\section{(A)}

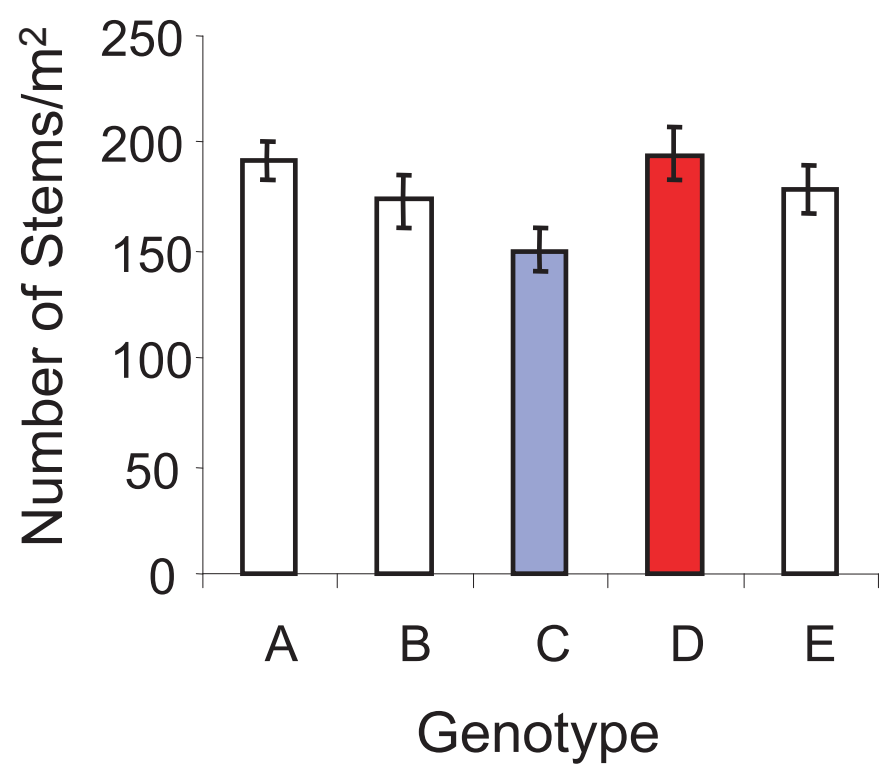

(B)

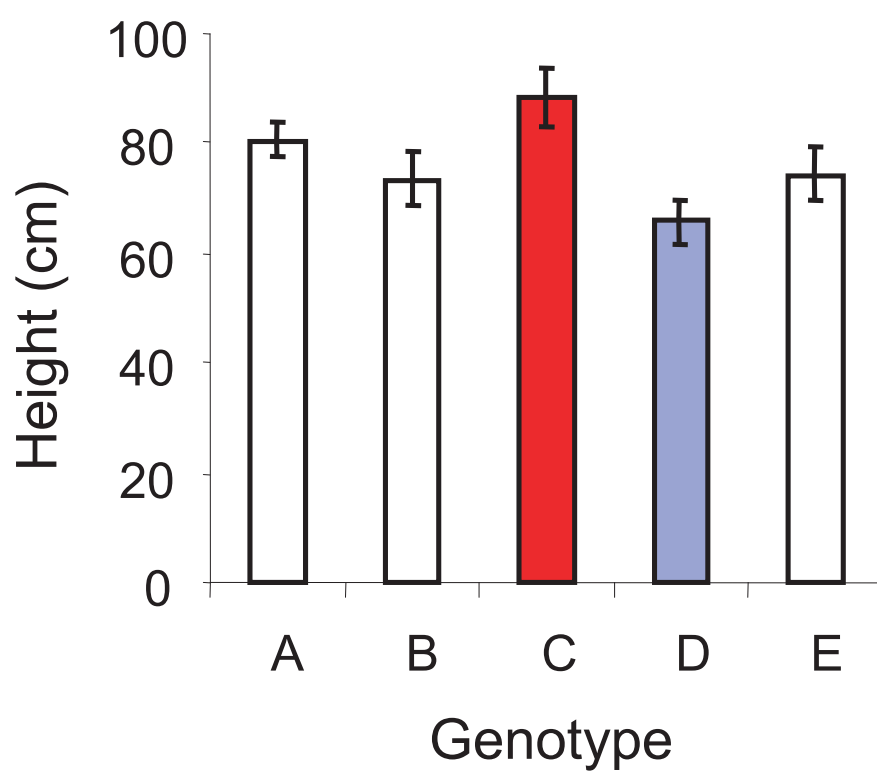

Figure 12. Stem density $(A)$ and average stem height $(B)$ differences between experimental smooth cordgrass clones. Significant differences between clones $C$ (blue) and $D($ red) illustrate a tradeoff in resource allocation between growth forms. 


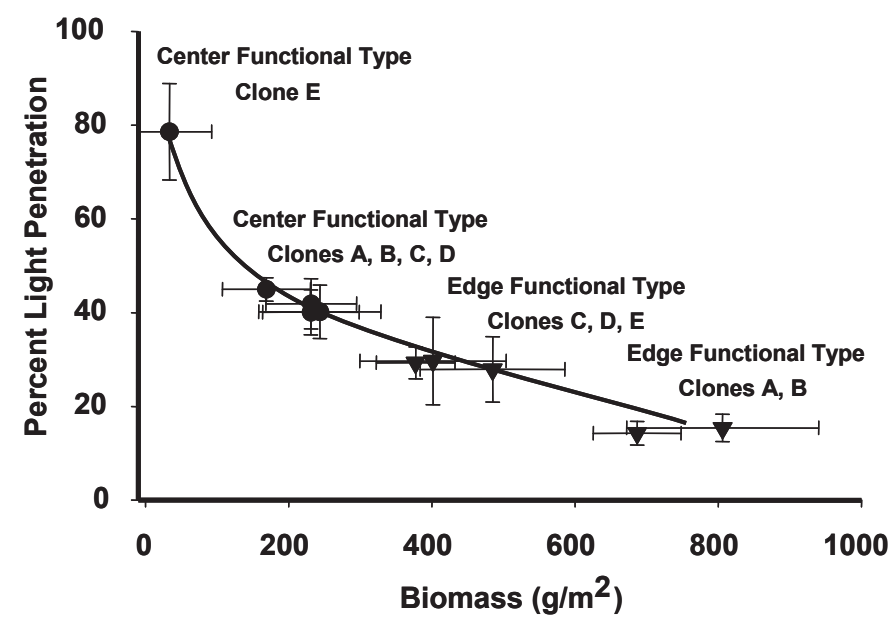

Figure 13. Smooth cordgrass clones classified as functional types according to the light and crowding conditions they provide for other colonizing plant species. Because clones characteristically undergo a process of center senescence, the function they provide at the center to potential colonists does not necessarily match the function they provide at the edge.

diversity might directly exclude some potential colonists, if none of the clones present were of the preferred functional type, or indirectly exclude them if their facilitative effect on a competing colonist was particularly strong.

A critical element promoting the establishment of clonal diversity in restored smooth cordgrass populations is gene flow, whether by clone fragmentation, by seed dispersal, or by pollen dispersal. While there are no published studies of pollen dispersal in smooth cordgrass, estimates for a closely related congener, saltmeadow cordgrass (Spartina patens), suggest average dispersal distances of just $3 \mathrm{~m}$ (Silander and Antonovics, 1979), so the potential for pollen dispersal to contribute significantly to interpopulation gene flow in smooth cordgrass is likely to be limited. On the other hand, direct evidence of the limits to seed dispersal in smooth cordgrass exists in the form of local genetic structure developing within young populations, as exemplified by elevated levels of genetic relatedness among neighboring clones (Travis and others, 2004). Locally structured populations likely develop as a result of seeds germinating in close proximity to their parents and siblings, which creates the potential for inbreeding among genetic relatives (beyond that which may occur through self-fertilization). Nevertheless, seed dispersal may be enhanced by the presence of open water margins at the edges of populations, as suggested by a study that tracked smooth cordgrass recovery following a dieback from a severe drought (Edwards and others, 2005). In this instance, many seedlings could be clearly observed within the recovering marsh, which was both slightly more genetically diverse than and slightly differentiated from an adjacent population that had remained relatively unaffected by the drought. These results suggest that these seedlings had germinated from seeds rafting in from other areas. The rafting of clone fragments has also been observed (Proffitt and Young, 1999), but may be an effective form of dispersal only during high level disturbances. Overall, the combined mechanisms of clone fragmentation and seed dispersal have resulted in a general pattern of genetic isolation-by-distance in smooth cordgrass, with a relatively high degree of population mixing at distances of up to approximately $350 \mathrm{~km}$ (Travis and Hester, 2005) (fig. 14).

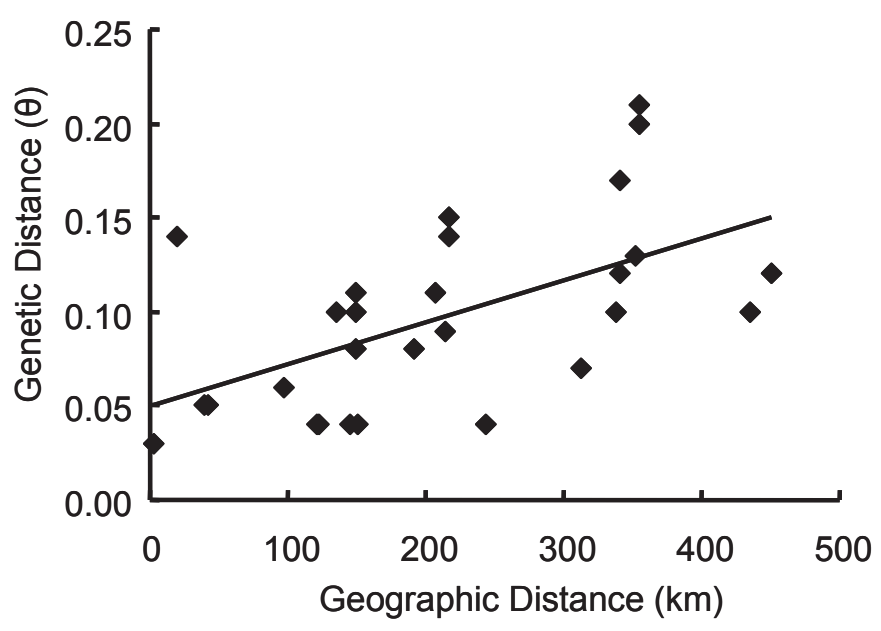

Figure 14. Genetic isolation-by-distance in smooth cordgrass, where $\theta$ represents the proportion of overall genetic variation attributable to differentiation among populations. Values of $\theta$ do not generally begin to exceed 0.15 , considered a moderate degree of genetic differentiation, until geographic distances exceed 300 $400 \mathrm{~km}$.

Ongoing research at the USGS National Wetlands Research Center (Lafayette, La.) is directly addressing issues of smooth cordgrass transplantation conducted for the purpose of salt marsh restoration, as well as the potential for outbreeding depression associated with transplantation activities. The success of restoring habitats through the transplantation of plant materials depends critically on the degree to which the donor populations happen to be preadapted to the restoration site, which may be a simple matter of physical proximity. Assessing levels of preadaptation may be greatly simplified through the use of neutral genetic markers in species such as smooth cordgrass, which exhibit a pattern of isolation-by-distance. Using a common-garden approach, a comparison of growth and reproductive performance among representatives from 23 smooth cordgrass populations collected at sites ranging from Texas to Maine is being conducted in order to determine the strength of the relationship between preadapation and geographical and latitudinal distance from the donor site (fig. 15). In addition, genetic differentiation between each donor site and a natural population growing immediately adjacent to the common-garden site is being evaluated to determine the comparative value of DNA fingerprinting as a predictor of preadaptation. Eight clones have been transplanted from each donor site and grown in a randomized block configuration 
(A)

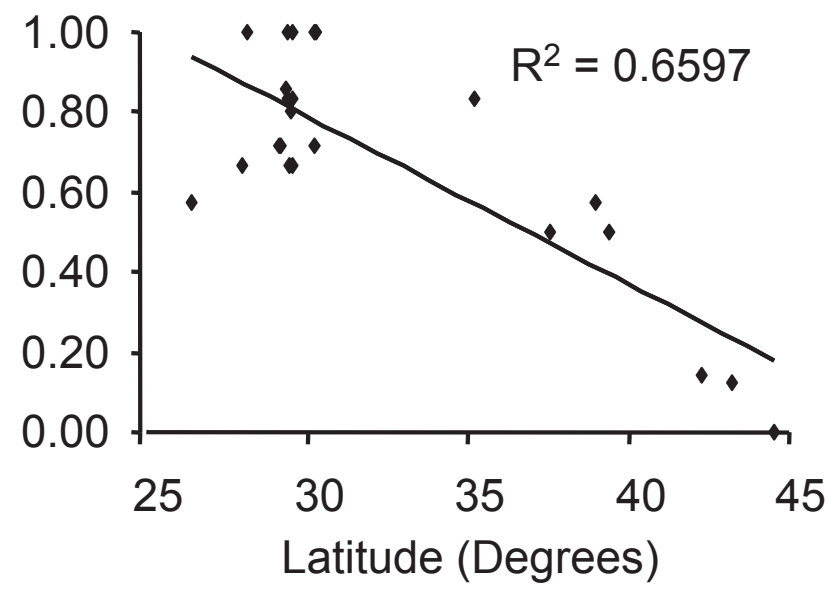

(B)

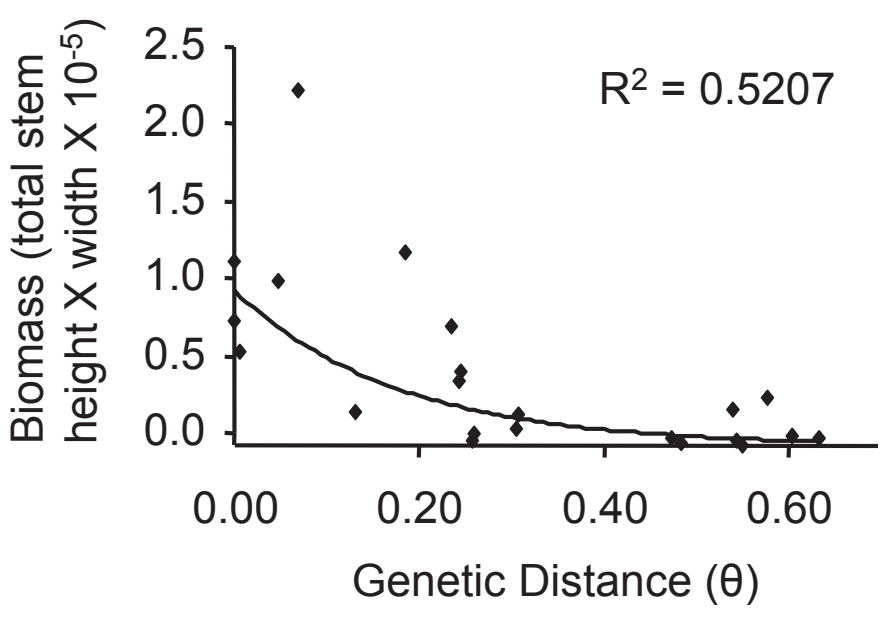

Figure 15. The effects of smooth cordgrass transplantation on survival and growth: (A) Survivorship correlates most strongly with the latitude of the donor site, with the high latitude populations suffering the highest mortality in Louisiana at a latitude of 25 degrees; (B) Growth (measured using a surrogate for biomass) correlates most strongly with the level of genetic differentiation between the donor populations and a reference population growing adjacent to the common-garden site.

over a slight elevational gradient at the Sabine NWR. Nine independent variables are being used to compare survival, growth, photosynthetic rate, and reproduction. A multivariate stepwise discriminant function analysis has identified a group of 5 variables that are useful in discriminating among the donor materials, while a structural equation modeling approach is being used to determine the relative contributions of geographic versus genetic distance in predicting variations in performance.

\section{Summary and Recommendations}

The overall implications of this research for smooth cordgrass restoration can be summarized as follows. First, smooth cordgrass plants selected for restoration that are low in genetic diversity, as measured by statistics such as average heterozygosity, will be at a competitive disadvantage relative to those representing natural populations. As shown, natural levels of genetic diversity develop quickly through passive colonization as long as a ready source of immigrants is available, and most actively planted clones will have been selected for growth characteristics that are reflective of high levels of genetic diversity. Thus, genetic diversity is unlikely to affect the immediate success of smooth cordgrass restorations, but rather will only become an issue if conditions leading to inbreeding act over time to lower it significantly. Second, the primary circumstance promoting inbreeding is low clonal diversity, which can develop through the passive colonization of physically isolated sites or the active planting of sites with a highly limited number of smooth cordgrass clones. This is largely a consequence of the ability of smooth cordgrass to rapidly overgrow sites via clonal spread, coupled with the inability of seedlings to become established once colonization is complete. Clonal diversity also ensures maximal coverage of sites varying in key environmental parameters such as elevation and facilitates the development of structural heterogeneity, ultimately leading to colonization by a diverse assemblage of plant species characteristic of gulf coast salt marshes. The continual decline in clonal diversity that occurs over thousands of years in smooth cordgrass populations renders it particularly important that high levels of clonal diversity be established at the outset of any restoration project in order to assure its long-term viability. Finally, attention should be paid, at the outset of any smooth cordgrass restoration project involving active transplantation, to the genetic and geographic distances between the donor and recipient sites. Materials taken or developed from distant sources may be maladapted to the restoration site and/or may contain genes that do not mix well with those of adjacent populations.

The overall recommendations for habitat restoration using smooth cordgrass stemming from this research are straightforward. Passive colonization is generally a highly effective method of restoring natural levels of genetic and clonal diversity on created sites; however, if a site is particularly isolated, such as would be expected for a barrier island, or if the potential for erosion of the site is particularly high, transplantation may still be desirable. In the latter situation, planting the donor materials at relatively low densities would be optimal for promoting natural levels of diversity. This practice will provide ample opportunity for crossbreeding with clones from neighboring populations and recruitment of the resultant seedlings prior to the complete coverage of the site. In the case of isolated sites, there is simply no substitute for developing plant materials that are 
highly diverse genetically and clonally prior to initiating the restoration program; otherwise, the low clonal diversity thus established may doom the resulting population to extinction, which may only require a single catastrophic event such as a disease outbreak to occur. In all situations, care should be taken not to transplant materials across donor and transplantation sites that are separated by more than approximately $300-400 \mathrm{~km}$ unless the proper steps have been taken to assure adequate levels of preadaptation. While these simple guidelines cannot anticipate every possible contingency, such as the effects of major storm events or human errors committed during preparation of the restoration site, if properly followed they should help to optimize the viability of restored smooth cordgrass populations and greatly enhance their probability of persisting well into the future.

\section{References Cited}

Bruno, J. F., 2000, Facilitation of cobble beach plant communities through habitat modification by Spartina alterniflora: Ecology, v. 81, p. 1,179-1,192.

Edwards, K. R., Travis, S. E., and Proffitt, C. E., 2005, Genetic effects of a large-scale Spartina alterniflora (smooth cordgrass) dieback and recovery in the northern Gulf of Mexico: Estuaries, v. 28, p. 204-214.

Egerova, J., Proffitt, C. E., and Travis, S. E., 2003, Facilitation of survival and growth of Baccharis halimifolia L. by Spartina alterniflora Loisel in a created Louisiana salt marsh: Wetlands, v. 23, p. 250-256.

Hartman, J. M., 1988, Recolonization of small disturbance patches in a New England salt marsh: American Journal of Botany, v. 75, p. 1,625-1,631.

Proffitt, C. E., Chiasson, R. L., Owens, A. B., Edwards, K. R., and Travis, S. E., 2005, Spartina alterniflora genotype influences facilitation and suppression of high marsh species colonizing an early successional salt marsh, Journal of Ecology: v. 93, p. 404-416.

Proffitt, C.E., Travis, S. E., and Edwards, K. R., 2003, Genotype and elevation influence Spartina alterniflora colonization and growth in a created salt marsh: Ecological Applications, v. 13, p. 180-192.

Proffitt, C. E., and Young, J., 1999, Salt marsh plant colonization, growth, and dominance on large mudflats created using dredged sediments, in Rozas, L. P., Nyman, J. A., Proffitt, C. E., Rabalais, N. N., Reed, D. J., and Turner, R. E., eds., Proceedings -- Recent research in coastal Louisiana -- natural system function and response to human influence: Louisiana Sea Grant College Program, Baton Rouge, Louisiana, p. 218-228.
Silander, J. A., and Antonovics, J., 1979, The genetic basis of the ecological amplitude of Spartina patens I. morphomoetric and physiological traits: Evolution, v. 33, p. 1,114-1,127.

Travis, S., Proffitt, E., Edwards, K., Hartman, G., and Haigh, G., 2002a, Text box 7.2 -- Ongoing dredged material marsh research in the Sabine National Wildlife Refuge, in Turner, G., and Streever, W., Approaches to coastal wetlands restoration -- Northern Gulf of Mexico: The Hague, SPB Academic Publishing, p. 81-82.

Travis, S. E., and Hester, M. W., 2005, A space-for-time substitution reveals the long-term decline in genotypic diversity of a widespread salt marsh plant, Spartina alterniflora, over a span of 1,500 years: Journal of Ecology, v. 93, p. 417-430.

Travis, S. E., Proffitt, C. E., Lowenfeld, R. C., and Mitchell, T. W., 2002b, A comparative assessment of genetic diversity among differently aged populations of Spartina alterniflora on restored versus natural wetlands: Restoration Ecology, v. 10, p. 37-42.

Travis, S. E., Proffitt, C. E., and Ritland, K., 2004, Population structure and inbreeding vary with successional stage in created Spartina alterniflora marshes: Ecological Applications, v. 14 , p. 1,189-1,202. 